\title{
REVIEW OF THE INSECTIVORA \\ FROM THE EARLY MIOCENE SHARPS \\ FORMATION OF SOUTH DAKOTA ${ }^{1}$
}

\author{
By J. H. HuTCHISON ${ }^{2}$
}

\begin{abstract}
Five of the seven reported insectivore taxa from the Sharps Formation (early Arikareean) of South Dakota are considered valid: Ocajila makpiyahe, Proscalops evelynae, Quadrodens wilsoni, Domnina greeni, D. dakotensis. One additional genus of shrew, Trimylus, is added to the fauna. Quadrodens is the senior synonym of Palaeoscalopus and is regarded as a talpid.
\end{abstract}

\section{INTRODUCTION}

In two papers covering the early Miocene (early Arikareean) vertebrate faunas from the Sharps Formation of the Wounded Knee area of southwestern South Dakota, Macdonald (1963, 1970) described six new species and three new genera of insectivores. A survey of the more recent paper and subsequent examination of the figured material indicates a need for some taxonomic revision and re-allocation of several of his specimens.

\section{METHODS}

Measurements were made with a Gaertner measuring microscope and are given to the nearest hundredth of a millimeter $(\mathrm{mm})$. Length of lower teeth equals the maximum possible length of parallel planes normal to a best fit line along the lingual margin of the tooth, with entoconid perpendicular to plane of view. Width equals the maximum width between parallel planes parallel to the length line. All specimens are conserved in either the Museum of Geology, South Dakota School of Mines and Technology (SDSM) or the Natural History Museum of Los Angeles County (LACM).

\section{SYSTEMATICS}

FAMILY Erinaceidae Fischer von Waldheim, 1817

SUBFAMILY Galericinae Pomel, 1848

TRIBE Echinosoricini (Cabrara, 1925) Gill, 1872

GENUS Ocajila Macdonald, 1963

Ocajila makpiyahe Macdonald, 1963

Macdonald (1963) initially described Ocajila makpiyahe on a single dentary fragment with $\mathrm{M}_{2}-\mathrm{M}_{3}$, but he made no subfamily assignment of the

${ }^{1}$ Review COMMitTEe For THIS CONTRIBUtion

William A. Clemens

Jason A. Lillegraven

David P. Whistler

${ }^{2}$ Museum of Paleontology, University of California, Berkeley, California 94720 
genus. Van Valen (1967: 262) placed Ocajila in the tribe Echinosoricini and suggested that the type jaw "may represent the otherwise unknown lower dentition of Brachyerix but is more probably a synonym of the echinosoricine Lanthanotherium." The lower dentition of Brachyerix has subsequently been identified (Rich and Rich, 1971) and is quite unlike Ocajila. The reduction of the paralophid and low profile of the molars support the placement in the Echinosoricini and close relationship with Lanthanotherium.

Subsequently Macdonald (1970) referred two new specimens to Ocajila makpiyahe, one of which he figured. He stated (p. 19) that "the $\mathrm{M}_{1}$ of LACM 9380 represents the first record of this tooth. It is an enlarged version of $\mathbf{M}_{2}$ with no significant variations in the pattern." LACM 9380 is referable to the soricid species Trimylus (see below). The second referred specimen (LACM 9491 ) is referable to $O$. makpiyahe but contributes no new information.

\section{FAMILY Talpidae Fischer von Waldheim, 1817 \\ SUBFAMILY Proscalopinae K. M. Reed, 1961 \\ GENUS Proscalops Matthew, 1901 \\ Arctoryctes Matthew, 1907}

Before any discussion of the evolutionary position of Proscalops evelynae from the Sharps Formation is undertaken, the probable stratigraphic position of the types of the named species of Proscalops needs clarification. The type localities of P. tertius K. M. Reed, 1961, P. terrenus (Matthew, 1907), and $P$. secundus Matthew, 1909 lack precise data as to location or formation or both. However, study of isolated teeth (to be published elsewhere) from known formations in South Dakota and adjacent states provides a reference to which the probable chronostratigraphic position of those type specimens may be determined. K. M. Reed (1961) states that P. tertius came from the "White River fm.," possibly Brule, "Badlands, South Dakota.", The presence of Oligoscalops in the lower member (Scenic Member) of the Brule Formation (K. M. Reed, 1961, and unpublished) and the slightly more advanced character of $P$. evelynae from the Sharps Formation which overlies the Brule Formation indicate that $P$. tertius is probably from the Poleslide member of the Brule Formation. This assumption is strengthened by a specimen of the $\mathrm{P}^{4}-\mathrm{M}^{\mathbf{1}}$, LACM 1493 from locality 1990, from the Poleslide Member in the Wounded Knee area that is essentially identical with $P$. tertius; however, the possibility that the type of P. tertius is from the lower part of the Sharps Formation or is conspecific with $P$. evelynae (see below) cannot be objectively ruled out with the present small sample sizes.

Macdonald $(1963,1970)$ has concluded that the type skull of $P$. secundus may have come from the upper portion of the Monroe Creek Formation or the lower Harrison Formation. Although lack of lower teeth of this type prohibit a refined interpretation of its evolutionary stage, Macdonald's conclusion is in agreement with the supposed position of $P$. secundus in the biostratigraphic series that has been based upon upper molar and premolar 



Figure 1. Proscalops evelynae (Macdonald, 1963), LACM 21416, incomplete rostrum with right $\mathrm{I}^{3}$ to $\mathrm{P}^{4}$ and lingual moieties of $\mathbf{M}^{1}-\mathrm{M}^{2}$ and left $\mathrm{C}$ to $\mathbf{M}^{1}$; $\mathrm{A}$, palatal view; $B$, lateral view of left side. Scale line equals $1 \mathrm{~mm}$. 
specializations. P. terrenus is a form species based on the humerus. Specimens referred to this species range in age from Whitneyan (Poleslide Member of Brule Formation) to Hemingfordian (Split Rock Formation, Wyoming). Thus, the concept of $P$. terrenus more than covers the entire chronostratigraphic span of all the species of Proscalops named on skulls and jaws. Macdonald (1963: 170) stated in regard to the type humerus of $P$. terrenus that "We can assume that the specimen was found anywhere between Porcupine Creek and the top of the divide east of Wounded Knee creek. The reference to "Upper Rosebud" [by Matthew, 1907] probably precludes the possibility that the type came from beds below the Harrison." Although Macdonald (1970:24) later suggested on less objective criteria that the type came from the Sharps Formation, I accept his original placement. P. terrenus is probably a valid species. Proscalopine teeth from the Harrison Formation near Agate, Nebraska, represent either an advanced species of Proscalops (more advanced than $P$. secundus) or a primitive species of Mesoscalops.

At present there are many reasons to assume that the sequence Oligoscalops galbreathi (C. A. Reed, 1956) - P.tertius - P. evelynae - P. secundus - Mesoscalops K. M. Reed represents a phyletic lineage with gaps. O. galbreathi was first named on the basis of a humerus as Arctoryctes galbreathi C. A. Reed, 1956 then later named again as Oligoscalops whitmanensis K. M. Reed, 1961 on the basis of a skull from Wyoming and a referred jaw from the same locality as the humerus in northeastern Colorado; there seems to be no reason to assume that the humerus belongs to a different species than the skull. P. miocaenus Matthew, 1901 may also belong in the sequence and on size and available dental characters (K. M. Reed, 1961) would fall between Oligoscalops and P.tertius.

Proscalops evelynae (Macdonald), 1963

Domninoides evelynae Macdonald, 1963

Arctoryctes terrenus Matthew, 1907 in part, Macdonald, 1963

Proscalops evelynae (Macdonald), Hutchison, 1968, including

Arctoryctes terrenus of Macdonald, 1963

Proscalops evelynae (Macdonald), Macdonald, 1970

Arctoryctes terrenus Matthew in part, Macdonald, 1970

A previously unpublished rostrum with $\mathrm{C}-\mathrm{M}^{1}$ and fragments of the $\mathrm{M}^{2}$ (LACM 21416 from locality 6898 [Fig. 1]), collected by Mr. Robert Machris, aids in comparing Proscalops evelynae (previously known only from the type, incomplete mandible, and from humeri) with other proscalopines known from skulls.

The type mandible (SDSM 5338) of Proscalops evelynae was originally described under another genus and has not previously been compared in detail to known jaws of other species of Proscalops. There is a chronological trend in Proscalops towards increasing hypsodonty of the molars. P. evelynae appears to be slightly more hyposodont, has greater extension of the enamel down the 
labial side of the roots, and has narrower anterior cingula than in P. tertius, $P$. miocaenus, and Oligoscalops. In size of teeth $P$. evelynae agrees closely with $P$. tertius but is significantly larger than P. miocaenus and Oligoscalops (see Macdonald, 1963, and K. M. Reed, 1961 for measurements). The low longitudinal crest (entocristid) at the base and lingual opening of the talonid valley is similar in all three species. P. evelynae differs markedly from Mesoscalops scopelotemos K. M. Reed, 1960, which has greater crown height, enamel extension, very high entocristid, and better developed cingular shelf between the labial bases of the protoconid and hypoconid.

The rostrum (LACM 21416) lacks the tip of the snout and posterolateral margins of the palate, thus only the left $\mathrm{M}^{1}$ and lingual shelves of the right $\mathrm{M}^{1-2}$ are preserved. Preceding the $\mathrm{P}^{4}$ 's, three teeth and two alveoli (one with root) are preserved on the left side and four teeth on the right side. Following the dental terminology of K. M. Reed (1961), these are $I^{3}, C, P^{2-3}$. The $I^{3-} P^{3}$ are unicuspid and single rooted with ovate to drop-shaped cross-sectional outlines. $\mathrm{I}^{3}$ is the smallest tooth and canine the largest between the $\mathrm{I}^{3}$ and $\mathrm{P}^{4}$ with $\mathrm{P}^{2}-\mathrm{P}^{3}$ subequal in size (Table 1). The $\mathrm{P}^{4}$ supports a single labial blade and lingual shelf with cusp. A minute cusp on the anterior side and near the base of the paracone represents the remnant parastyle as in Proscalops tertius, $P$. miocaenus, and $P$. secundus but not Mesoscalops in which it is absent. K. M. Reed (1961:286) states that the parastyle is absent in all Proscalops and Mesoscalops but in the types of all Proscalops species my observations indicate

TABLE 1

Measurement (in mm) of the upper teeth of Proscalops evelynae, LACM 21416

\begin{tabular}{lllll}
\hline \multirow{2}{*}{ P4* } & & Left & Right \\
& length & width & 2.27 & - \\
P3* & length & 2.28 & - \\
& width & 0.87 & 0.87 \\
P2 & length & 0.70 & 0.68 \\
& width & 0.84 & 0.87 \\
P1 & length & 0.60 & 0.61 \\
& width & 0.93 & 0.69 \\
C & length & 0.74 & 0.55 \\
& width & - & 0.48 \\
\hline
\end{tabular}

*P4 maximum length between parallel planes perpendicular to the line connecting the parastyle and posterior tip of ectoloph (this is not the parameter used but undefined by K. M. Reed, 1961). Unicuspid tooth length is the maximum crosssectional diameter 


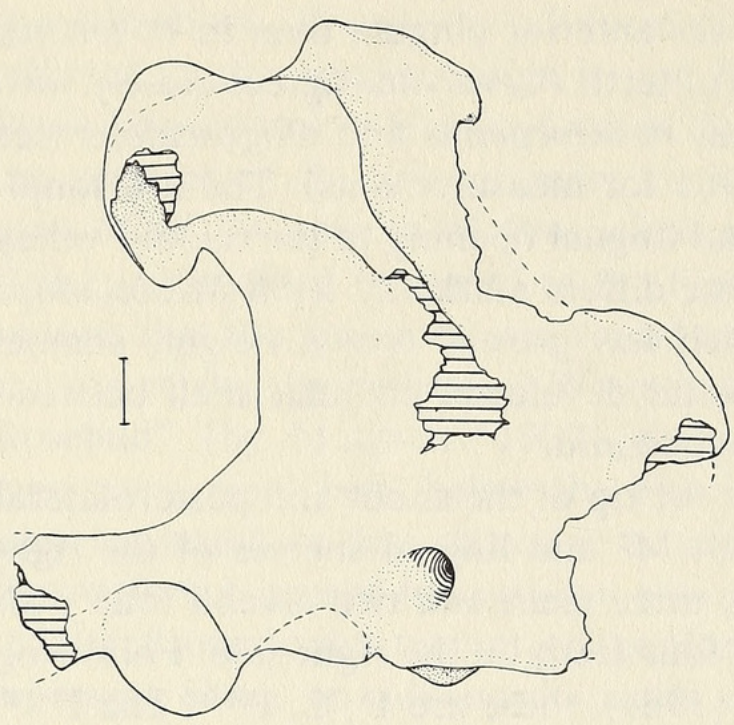

A

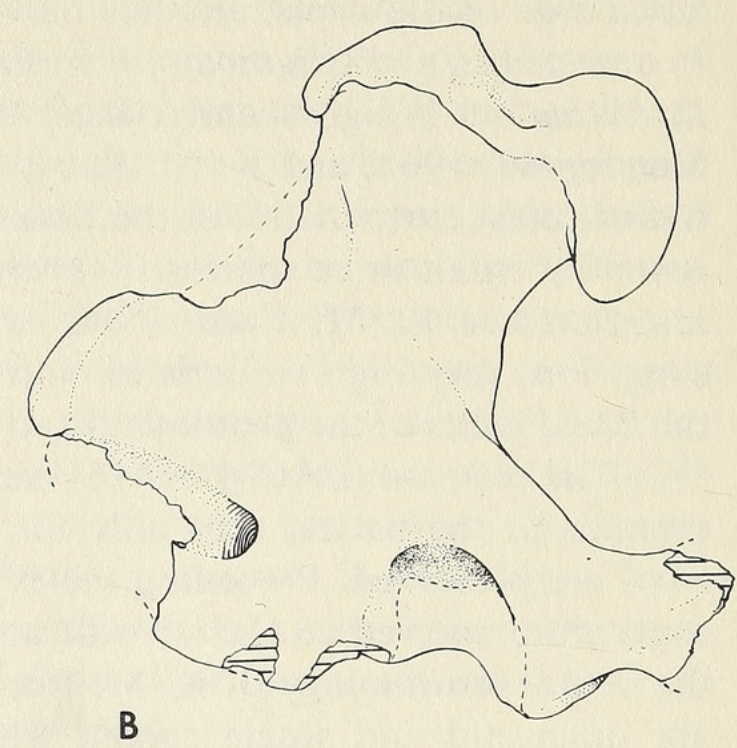

B

Figure 2. Proscalops evelynae (Macdonald, 1963), LACM 9362, damaged right humerus; A, anterior view; B, posterior view. Scale line equals $1 \mathrm{~mm}$.

a small vertical ridge or distinct minute cuspation occurred in the ancestral area of the parastyle. The lingual cusp is rather posteriorly situated as in $P$. tertius but more shelflike, although, not to the extreme as in $P$. secundus. There is no indication of a second cusp behind the main lingual cusp as in the unworn $\mathrm{P}^{4}$ of Mesoscalops. The molars as preserved agree closely with $P$. tertius in presence of well-developed metaconules (hypocone of K. M. Reed), protoconules (protostyle of K. M. Reed), and minute "hypostyles." Despite the qualitative differences in degree of angulation and development mentioned by K. M. Reed (1961) between the molars of P. tertius and P. secundus, I believe that at present it is difficult to distinguish such features on worn teeth; the relative proportions or distinctness of these cusps change significantly due to differential wear and to stage of wear. Unworn teeth and an analysis of wear progression in larger samples of the various species are needed to evaluate these features. The rostrum agrees in detail with those already described by K. M. Reed (1961) for other species of Proscalops.

Measurements (following Reed and Turnbull, 1965) on 11 humeri (Fig. 2) from the LACM collections show a wide range in variation, with measurements of the smaller specimens ranging from 74 to $88 \%$ of the largest; however, the ratios of these measurements produced ranges essentially identical to those calculated by Reed and Turnbull (1965) for "Arctoryctes terrenus" except

Figure 3. Quadrodens wilsoni Macdonald, 1970; A, LACM 9331 (Type) occlusal view of $\mathbf{M}_{1}-\mathrm{M}_{2}$; B, SDSM 6244 (referred specimen of Palaeoscalopus) reversed occlusal outline of $\mathbf{M}_{1}-\mathbf{M}_{2}$, hachures indicate edge of apparently anomalous shear wear surface. C-E, SDSM 55135 (Type of Palaeoscalopus); C, reversed occlusal outline of $\mathbf{M}_{1}-\mathbf{M}_{2} ; \mathrm{D}$, lingual view of dentary fragment with $\mathbf{P}_{4}-\mathbf{M}_{3} ; \mathbf{E}$, occlusal view of $\mathrm{P}_{4}$ and antemolar alveoli; F, SDSM 6244, occlusal view of $\mathrm{P}_{4}$ and antemolar alveoli. Scale lines equal $1 \mathrm{~mm}$. 

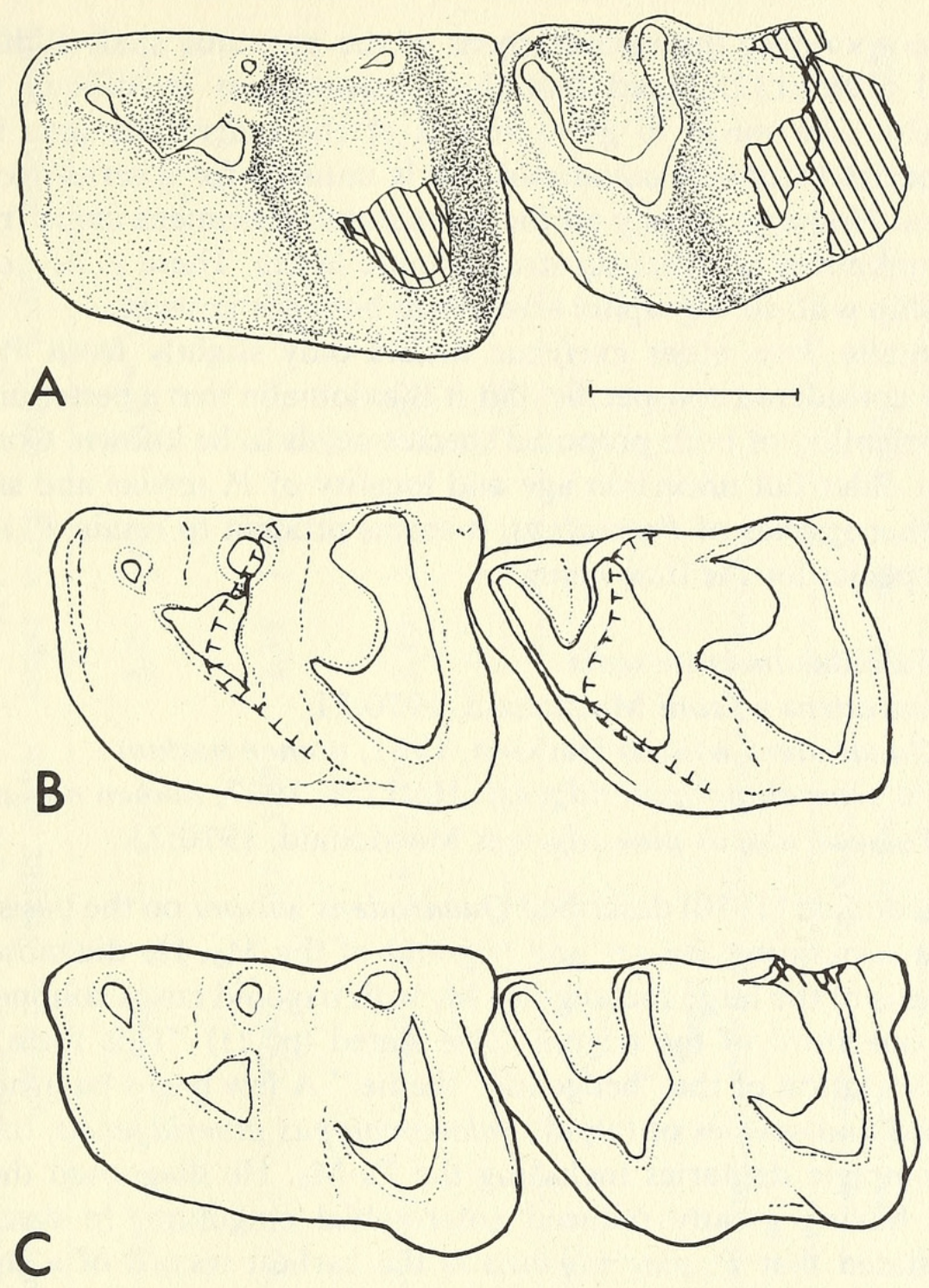

$\mathrm{E}$
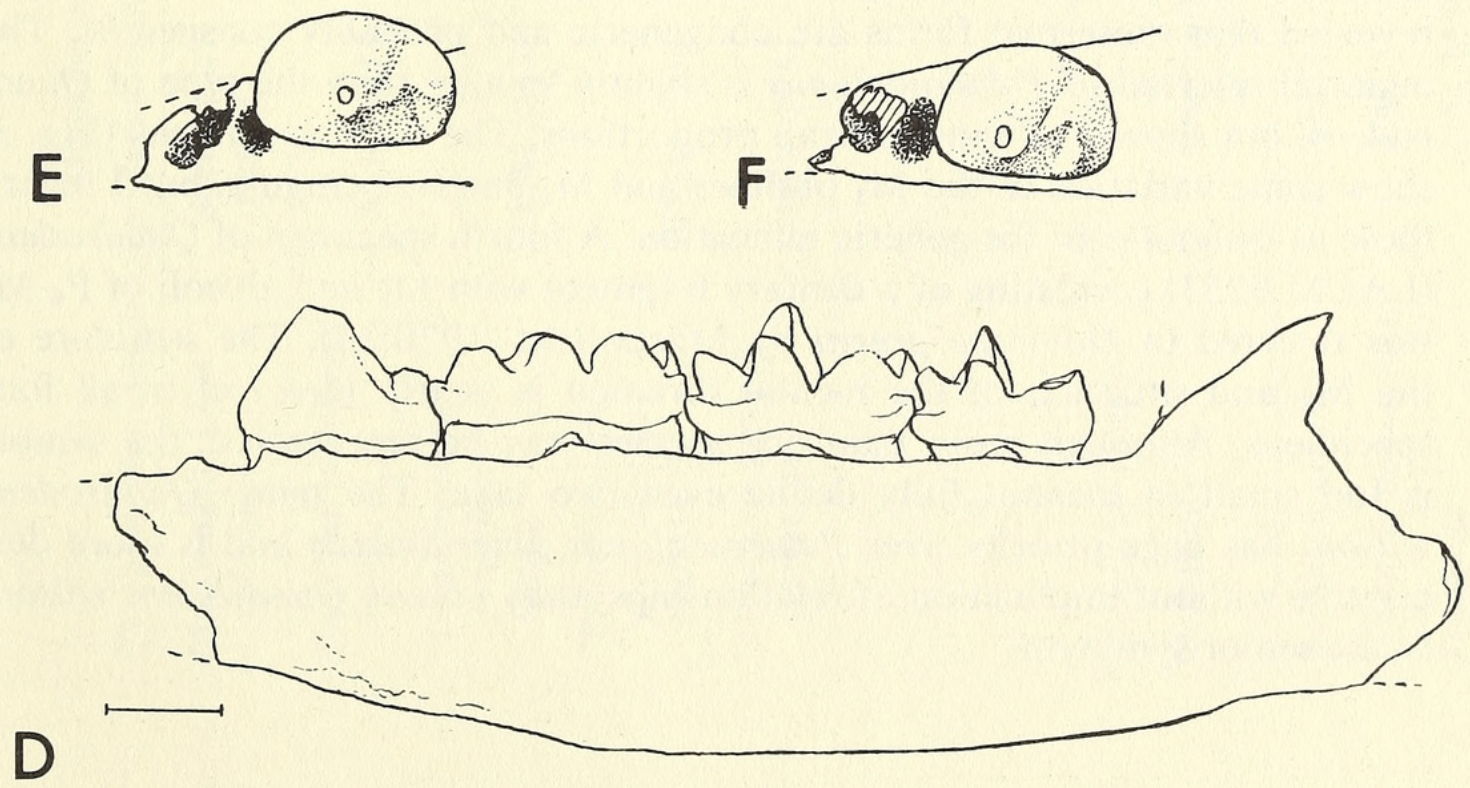
those incorporating the measurement of the proximal shaft width. Reed and Turnbull (1965:132) noted that this measurement is difficult to duplicate objectively. The range in gross size is of the magnitude seen within some living species (Scalopus aquaticus) but is unusual for a series from a specific local area. However, nearly all the measurable specimens came from different sites of unknown or differing stratigraphic levels. There is no consistent size relationship with stratigraphic level when both are known.

Dentally Proscalops evelynae differs only slightly from P. tertius and might be considered conspecific, but it is axiomatic that a better understanding of the variability of both proposed species needs to be known. Considering the probably older but uncertain age and locality of $P$. tertius and small samples of the other species of Proscalops, it seems prudent to retain P. evelynae as a distinct species for the time being.

Talpidae incertae sedis

Quadrodens wilsoni Macdonald, 1970:21

Quadrodens wilsoni Harksen, 1967, nomen nudum

Palaeoscalopus pineridgensis Harksen, 1967, nomen nudum

Palaeoscalopus pineridgensis Macdonald, 1970:23

Macdonald (1970) described Quadrodens wilsoni on the basis of a dentary fragment containing the $\mathbf{M}_{1}$ and trigonid of the $\mathbf{M}_{2}$. He diagnosed the genus on the basis of the large rectangular $\mathrm{M}_{1}$ with trigonid cusps confined to approximately one third of the trigonid. He stated (p. 21) "This form seems to be another variation of the "hedgehog" theme." A few pages later he described a new genus and species of talpid, Palaeoscalopus pineridgensis, on the basis of two incomplete dentaries including the $\mathrm{P}_{4}-\mathrm{M}_{3}$. He diagnosed the $\mathbf{M}_{1}$ of this form as having greatly reduced anterolabial cingulum. In discussion Macdonald stated that $P$. pineridgensis is the earliest record of a shrew-mole in North America.

There is a great similarity between Macdonald's figures (Figs. 6, 8) of Quadrodens and Palaeoscalopus and subsequent examination of the types revealed that these two forms are congeneric and probably conspecific. The material referred to Palaeoscalopus is slightly smaller than the type of Quadrodens, but shows the same overall proportions. The three specimens (Fig. 3) show some variation in the $\mathbf{M}_{1}$ outlines and $\mathbf{M}_{1}$ anterior cingula, but $\mathrm{I}$ regard these as insignificant for generic allocation. A fourth specimen of Quadrodens (LACM 9253) consisting of a dentary fragment with $\mathrm{M}_{2}$ and alveoli of $\mathrm{P}_{4}-\mathrm{M}_{3}$ was referred to Domnina greeni by Macdonald (1970:21). The structure of the $\mathrm{M}_{2}$ and situation of the mental foramen is nearly identical in all four specimens. Although more than one species may be represented, the sample is too small to meaningfully define even two taxa. The name Quadrodens wilsoni has page priority over Palaeoscalopus pineridgensis and is more descriptive without implication of relationships; thus I chose Quadrodens wilsoni as the senior synonym. 

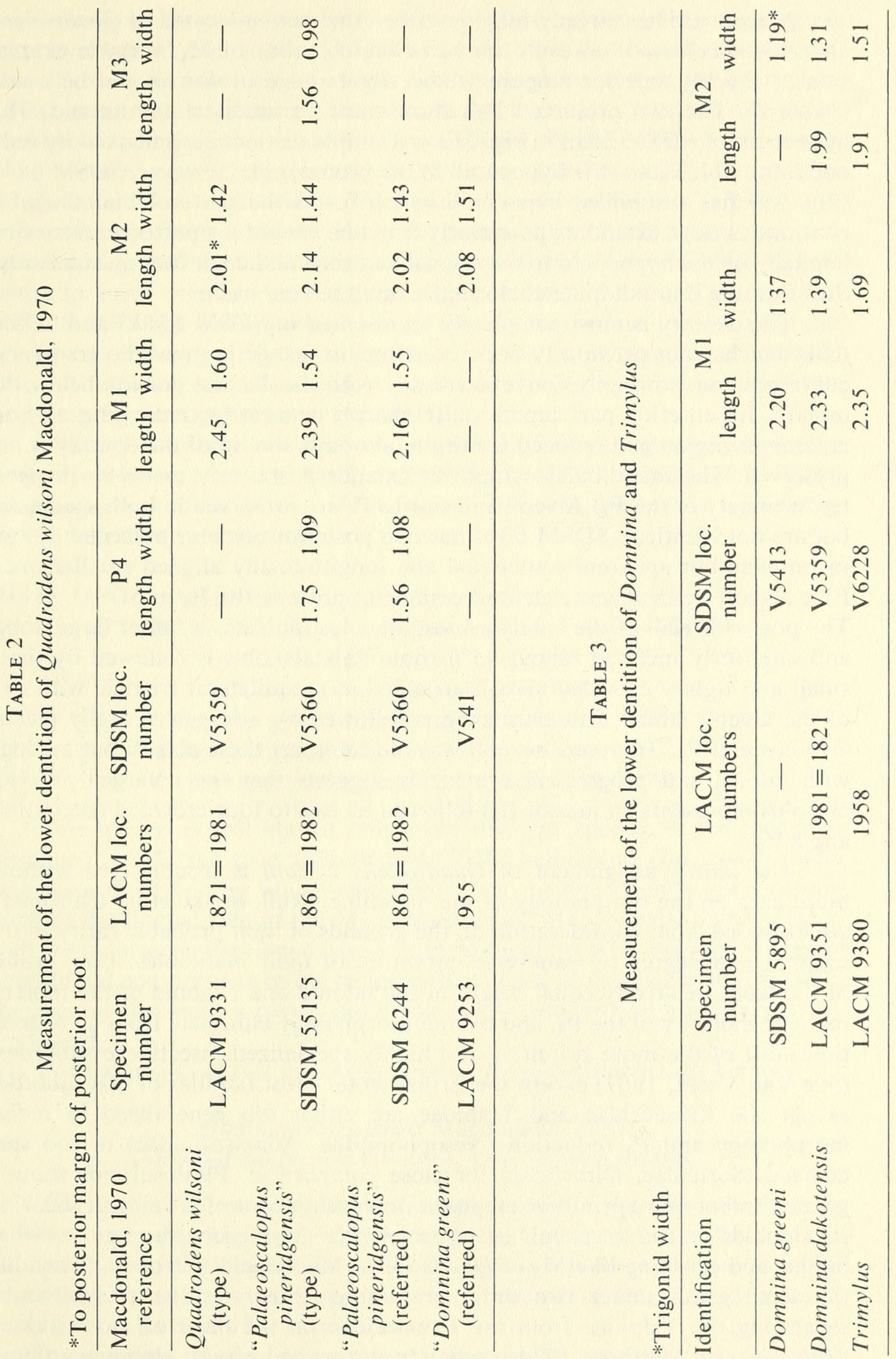
Macdonald has already fully described the teeth allocated to Quadrodens and Palaeoscalopus; however, the variation in outline of $\mathbf{M}_{1}$, variable expression of the $M_{1}$ anterior cingulum, and slight range in size should be noted (Table 2). The two preserved $\mathrm{P}_{4}$ 's show some variation of the talonid. The hypoconid of SDSM 55135 (Fig. 3E) is a simple distinct cusp flanked by only one ridge which joins the hypoconid to the protoconid. However, SDSM 5244 (Fig. 3F) has a subdued hypoconid which forms the posterolabial rim of a continuous ridge extending posteriorly from the base of the protoconid curving lingually on the hypoconid to the lingual margin and then deflecting anteriorly, thus forming (but not quite enclosing) a small talonid basin.

The dentary is most completely represented in SDSM 55135 and SDSM 6244 but has not previously been described in detail. It shows no transverse curvature and is broadly convex ventrally with the deepest portion below the molars. Its anterior part tapers quite sharply anteriorly, indicating a short antemolar region and reduced dentition, although the tip of the dentary is not preserved. The mandibular symphysis extends posteriorly to below the posterior moiety of the $\mathrm{P}_{4}$. Alveoli anterior to $\mathrm{P}_{\mathbf{4}}$ are preserved in both specimens but are not identical. SDSM 6244 has one posterior alveolus preceded by two incomplete but apparently subequal and longitudinally aligned smaller ones. Five alveoli (both incomplete and complete) precede the $\mathrm{P}_{\mathbf{4}}$ in SDSM 55135. The posterior wall of the anterior-most alveolus indicates a rather large, long, and anteriorly inclined (about $45^{\circ}$ ) root. This alveolus is followed by three small and tightly crowded alveoli arranged in a equilateral triangle with two of the alveoli labial. This clustering is followed by a larger centrally placed alveolus and $\mathrm{P}_{4}$. There are several ways to interpret these alveoli but analogy with talpids and progressive erinaceids suggests that the enlarged anterior alveolus represents an incisor $\left(\mathrm{I}_{2}\right)$ followed by two to four crowded antemolars and a $\mathrm{P}_{4}$.

The family assignment of Quadrodens wilsoni is troublesome without more data on the morphology of the mandible, skull, or skeleton. Chiroptera are excluded from consideration on the grounds of their probable rarity in the samples and degree of transverse curvature of their mandibles. Low profile of the teeth, relatively equal height of the talonid and trigonid of the molars, reduced molarity of the $\mathrm{P}_{4}$, and overall morphology eliminate from consideration most of the more primitive and highly specialized insectivore suborders (fide Van Valen, 1967) except the Erinaeceota. Most families of this suborder except the Erinaceidae and Talpidae are either too generalized in molar morphology and $\mathrm{P}_{4}$ reduction (Nesophonitdae, Adapisoricidae) or too specialized (Soricidae, Dimylidae) for close comparison. Plesiosoricids show a greater and/or more primitive emphasis on development of prominent shearing paralophids on the lower molars (especially the $\mathbf{M}_{1}$ ) in contrast to the rather bulbus and crushing-like $\mathrm{M}_{1}$ of Quadrodens. Macdonald's error in describing the same genus under two different families illustrates the difficulties of separating the Talpidae from the Erinaceidae on the basis of molars alone (Talpa incerta Matthew, 1924 is a brachyericine hedgehog). Members of both 
families may be characterized by loss of a distinct hypoconulid and merging of the hypolophid and entoconid of the molars. Most talpids and many erinaceids (Echinosoricinae, Erinaceinae) exhibit quadrate low crowned molars without great disparity between the talonids and trigonids. Quadrodens wilsoni resembles some erinaceids and differs from known talpids in: 1) even convexity of the lower margin of the dentary; 2) $\mathbf{M}_{1}$ larger than $\mathrm{M}_{2}$; and 3 ) basined (in one specimen of two) talonid on $\mathrm{P}_{4}$. Quadrodens resembles the Talpidae and differs from the Erinaceidae in: 1) lack of paraconid on $\mathrm{P}_{4} ; 2$ ) transverse basal posterior cingulum and posterolingual accessory cuspid on $\mathrm{M}_{1}-\mathrm{M}_{2}$; and 3) mental foramen small and not depressed into dentary. Although the anterior part of the dentary was apparently short, there is no obvious indication in the area of the $\mathrm{P}_{4}$ suggesting an enlarged incisor as in progressive erinaceids; however, talpids frequently develop a reduced dentition with prominent but not greatly hypertrophied lower incisor $\left(I_{2}\right)$.

Although the above comparisons may not lead to an obligatory conclusion of talpid affinities, I believe that Quadrodens wilsoni is a talpid and, on theoretical zoogeographical grounds (Hutchison, 1968:108), this species is probably aligned with the Proscalopinae.

FAMILY Soricidae Fischer von Waldheim, 1817

SUBFAMILY Heterosoricinae Viret and Zapfe, 1951

GENUS Domnina Cope, 1873

Domnina greeni Macdonald, 1963

Domnina greeni Macdonald, Hutchison, 1966

Domnina greeni Macdonald, Repenning, 1967

Domnina greeni Macdonald, Macdonald, 1970

This species is still known only from the type specimen; the specimen subsequently referred to it (Macdonald, 1970) belongs to Quadrodens. The teeth were described by Macdonald (1963) but the specimen is abraded and much of the lingual side of the $\mathrm{M}_{2}$ is worn away. Macdonald's (1963, Fig. 5, teeth are incorrectly captioned $\mathrm{M}_{2-3}$ ) illustration of the type indicates a greater longitudinal compression of the trigonid than exists on the specimen (Fig. 4C). The mental foramen is partly preserved below and just anterior to the $M_{1}$ hypoconid.

For discussion of this species see that of Domnina dakotensis below.

Domnina dakotensis Macdonald, 1970

\section{Domnina dakotensis Harksen, 1967, nomen nudum}

This species, known only from the type mandible, was characterized by its widely open $M_{1}$ trigonid and closure of the $M_{1}-M_{2}$ talonid valleys by the entoconid crest (entocristid). In addition, there is a postsymphyseal foramen below the level of the $\mathrm{M}_{1}$ hypoconid and the root of the large incisor extends posteriorly as far as the $\mathrm{M}_{1}$ hypoconid.

Considering relative temporal and geographic proximity of Domnina 


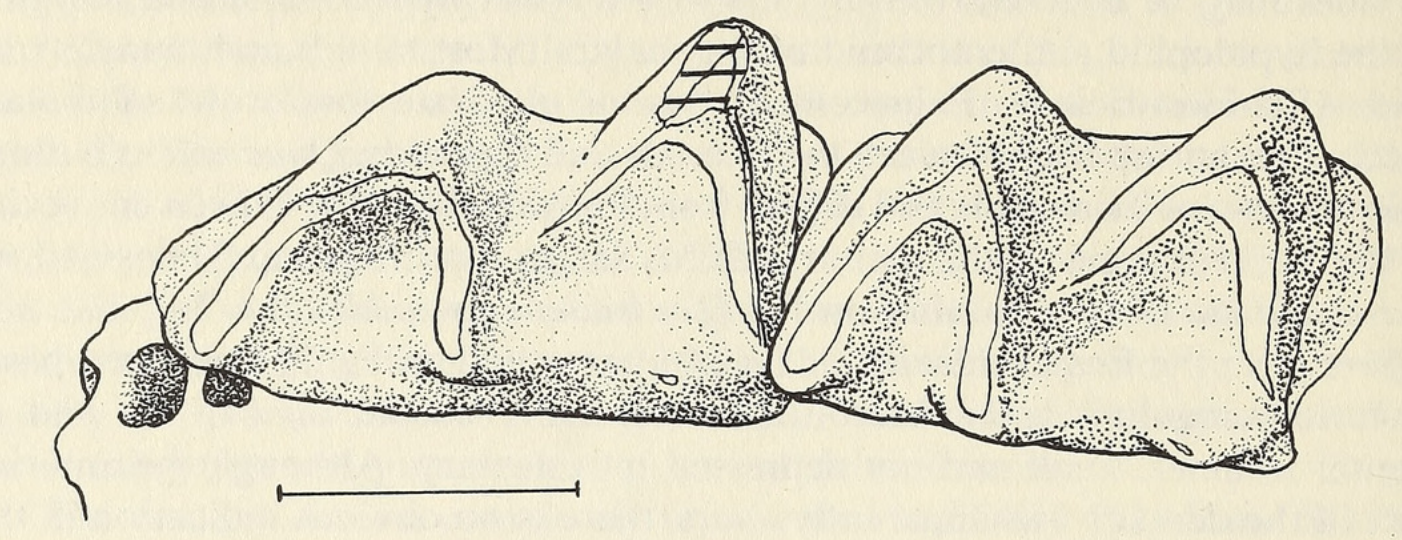

A
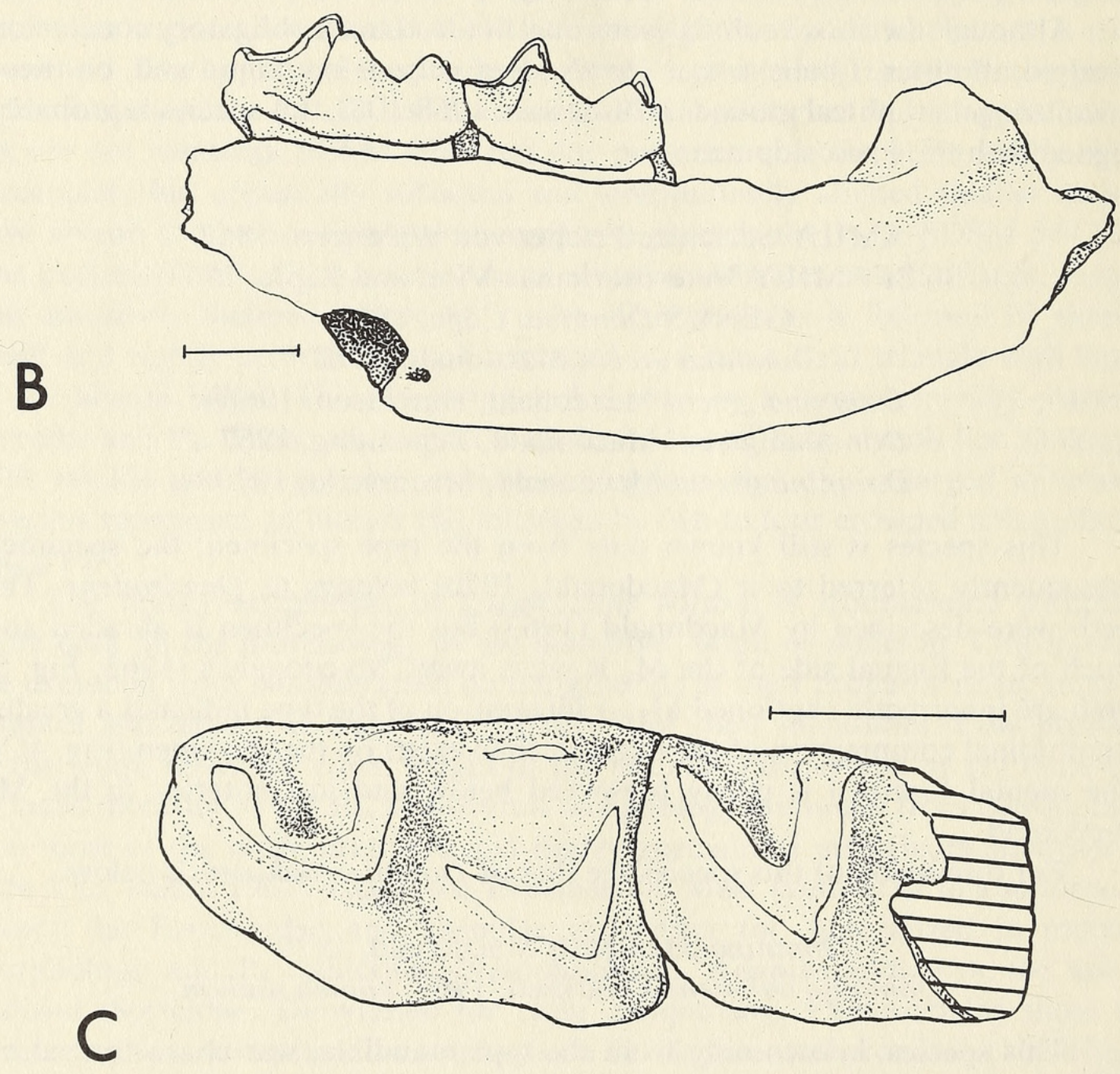

Figure 4. A-B Domnina dakotensis Macdonald, 1970, LACM 9351 (Type), A, lingual view of dentary fragment with $\mathbf{M}_{1}-\mathbf{M}_{2} ; \mathbf{B}$, occlusal view of $\mathbf{M}_{1}-\mathbf{M}_{2} ; \mathbf{C}$, Domnina greeni Macdonald, 1963, SDSM 5895 (Type), occlusal view of $\mathbf{M}_{1}-\mathbf{M}_{2}$. Scale lines equal $1 \mathrm{~mm}$. 
greeni and $D$.dakotensis, discussion of relationships of these two poorly known species is necessary. The relative openness of the $\mathrm{M}_{1}$ trigonid of $D$. dakotensis is not particularly diagnostic and may be the same as in D. greeni when relative differences in wear, preservation, and individual variation are considered. Macdonald (1970) stressed the uniqueness of the closure of the trigonid valley by the entoconid crest, but I fail to see any difference between the two species in the closure or height of the crest (compare Fig. 4B with Macdonald, 1963, Fig. 5). Indeed, Repenning (1967) characterizes the genus by the entoconid "united to the metaconid by a high ridge (entoconid crest)." Although the "diagnostic" characters are nullified, there are subtle differences between the two specimens which may be of specific significance when better samples are available. The postentoconid valley is comparatively well developed in $D$. greeni (as in D. gradata Cope, 1873) but absent in D. dakotensis (Fig. 4A). The presence or absence of this valley seems to be relatively constant in other species of shrews; however, if these specimens represent transition to a closedvalley condition, then variability in this character is significant. The molars of D. dakotensis appear to be relatively longer (Table 3), more delicate, and have perhaps a better-developed metastylar ridge on the metaconid than in $D$. greeni, although preservation of the $D$. greeni specimen is not ideal for comparison. In the absence of a larger sample of either species, it seems prudent to tentatively retain both species names on the basis of the above characters.

The closure of the postentoconid valley and delicacy of the molars suggests that Domnina dakotensis might be on the lineage of Paradomnina Hutchison, 1966 , but the relatively greater posterior extension of the incisor root, more posterior position of the postsymphyseal foramen, and perhaps fewer antemolars are specialized characters over the later Paradomnina. There are no serious obstacles to deriving $D$. dakotensis from $D$. gradata.

\section{GENUS Trimylus Roger, 1885 \\ Trimylus sp.}

Macdonald (1970:19, Fig. 4) figured a dentary fragment, LACM 9380, and referred it to Ocajila makpiyake. The deep robust jaw, position of the mental foramen, and construction of the teeth showed remarkable similarity to those features in the heterosoricine shrews, especially Trimylus. Subsequent examination of this specimen confirms its assignment to Trimylus.

Macdonald did not describe this specimen in detail and some diagnostic features are misleadingly illustrated or not figured. LACM 9380 consists of a midsection of the horizontal ramus containing $\mathbf{M}_{1}-\mathbf{M}_{2}$. The dentary (Fig. 5) is deep and robust with a large mental foramen set below the ectoflexus of the $\mathrm{M}_{1}$ in the posterior end of an elongate depression extending anterodorsad. A prominent postsymphyseal foramen opens anterolabially near the ventral margin of the dentary below the junction of the $M_{1}-M_{2}$. The dentary is broken off just anterior to this foramen with the break extending anterodorsally to just in front of the $M_{1}$. No part of the symphysis is preserved. The cavity for 

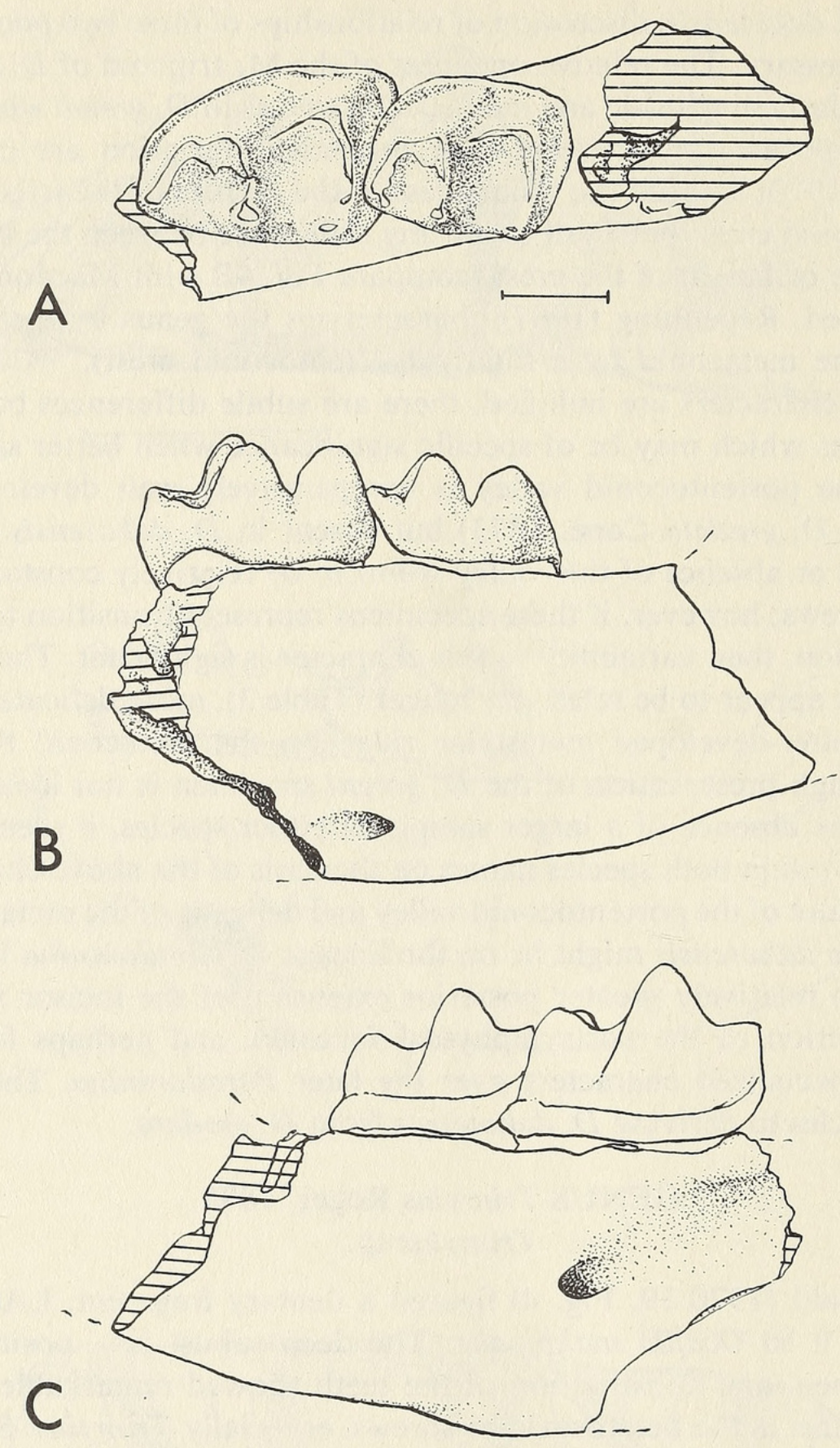

Figure 5. A-C, Trimylus sp., LACM 9380, dentary fragment with $\mathbf{M}_{1}-\mathbf{M}_{2} ; \mathrm{A}$, occlusal view; B, lingual view; C, labial view. Scale line equals $1 \mathrm{~mm}$.

the root of the large incisor extends as far as the symphyseal foramen but none of its external margins are preserved. Remains of one antemolar alveolus $\left(\mathbf{P}_{4}\right)$ are preserved just anterior to $\mathbf{M}_{1}$. There apparently is room for only one or two additional alveoli between the $\mathrm{P}_{4}$ and $\mathrm{I}_{1}$.

The molars are graded in size (Table 3) with the $M_{1}$ about one-third larger than $\mathbf{M}_{2} . \mathrm{M}_{1}$ resembles other Trimylus in its robust proportions and major features of the trigonid and talonid (see Mawby, 1960, Wilson, 1960, 
and Repenning, 1967). The anterior cingulum of $M_{1}$ is well defined but terminates labially to the lingual extremity of the paraconid. The hypolophid is well fused to the entoconid but a small hypoconulid persists in early wear high up the posterolabial flank of the entoconid. $\mathbf{M}_{2}$ resembles $\mathbf{M}_{1}$ but the trigonid is more closed thus shortening and compacting the tooth. A small (adventitous?) cuspid on the posterolabial flank of the paraconid occludes part of the trigonid valley. A slight vertical ridge on the posterolabial wall of the talonid indicates the position of the hypoconulid. Only the anterior root of the $\mathrm{M}_{3}$ is preserved. No pigmentation is evident on the teeth.

The massive construction of the jaw, large incisor, posteriorly-situated and recessed mental foramen, postsymphyseal foramen, strong size gradation of the robust molars with nearly complete fusion of the entoconid and hypolophid conspire to situate LACM 9380 firmly within the genus Trimylus (Mawby, 1960, Repenning, 1967).

The Sharps Formation specimen agrees better with near contemporary forms of Trimylus in North America than with later Miocene and Pliocene species of North America and Europe in its more anterior location of the mental foramen and incisor root and retention of vestiges of the hypoconulid on the molars. The Sharps specimen differs from $T$. dakotensis Repenning, 1967 in nearly complete fusion of $\mathbf{M}_{1}$ and $\mathbf{M}_{2}$ hypolophids to the entoconids, slightly larger size, persistent anterior cingulum on $\mathbf{M}_{1}$, and slightly more anterior position of the mental and postsymphyseal foramina. The Sharps specimen closely resembles $T$. compressus (Galbreath, 1953) in tooth morphology but differs in slightly more anterior situation of the mental and postsymphyseal foramina. The Sharps species differs from $T$. roperi in the anterior position of the mental and (?) post-symphyseal foramina, more anterior position of the $I_{1}$ root, and possibly the greater prominence of the hypoconulids.

Although nearest in time to Trimylus dakotensis (early Hemingfordian), the Sharps specimen seems a little closer to $T$. compressus (Orellan) in those meager features available, such as the greater coalescence of the $M_{1}-M_{2}$ hypolophids and entoconids and persistent $\mathrm{M}_{1}$ anterior cingulum. I think it prudent, however, to leave specific allocation in abeyance until more diagnostic material (i.e., antemolar region) is found and a better understanding of the variation of the named species is obtained.

\section{SUMMARY}

Of the seven insectivores reported from the Sharps Formation by Macdonald (1963, 1970), I recognize five of which two species are only tentatively retained as distinct. The shrew, Trimylus, is an addition to the Sharps Formation fauna. The revised insectivore fauna is as follows:

Family: Erinaceidae

Ocajila makpiyahe Macdonald, 1963 


\section{$2 \mathrm{BHL}$ Biodiversity Heritage Library}

Hutchison, J. Howard. 1972. "Review of the Insectivora from early Miocene Sharps formation of South Dakota." Contributions in science 235, 1-16. https://doi.org/10.5962/p.241219.

View This Item Online: https://www.biodiversitylibrary.org/item/214111

DOI: https://doi.org/10.5962/p.241219

Permalink: https://www.biodiversitylibrary.org/partpdf/241219

\section{Holding Institution}

Smithsonian Libraries

\section{Sponsored by}

Biodiversity Heritage Library

\section{Copyright \& Reuse}

Copyright Status: In Copyright. Digitized with the permission of the rights holder

Rights Holder: Natural History Museum of Los Angeles County

License: https://creativecommons.org/licenses/by-nc-sa/4.0/

Rights: https://www.biodiversitylibrary.org/permissions/

This document was created from content at the Biodiversity Heritage Library, the world's largest open access digital library for biodiversity literature and archives. Visit BHL at https://www.biodiversitylibrary.org. 